\title{
Good Questions 7: How Should Human Milk Banks be Regulated?*
}

\section{ABSTRACT}

The term "human milk" refers to breastmilk used for purposes other than feeding a mother's own infant, usually to directly meet the needs of other women's infants especially those who are critically ill. Historically, milk sharing has been done primarily through wet nursing, but human milk banking has been growing rapidly since the beginning of the twentieth century.

There are concerns because some banks operate in ways that are exploitative, unsanitary, or provide milk to people who use it for questionable purposes. There is a clear need for regulation of milk banking, not only to limit undesired practices but also to facilitate good practices. This essay suggests a framework for legislation that supports milk banks in achieving their goals while also ensuring that the public's interests are served.

Keywords: human milk, donor milk, milk banking, regulation, commodification, private law

\section{INTRODUCTION}

The term "human milk" refers to breastmilk used for purposes other than feeding a mother's own infant, usually to directly meet the needs of other women's infants. Human milk has been exchanged since time immemorial through wet nursing, but in recent decades there has been rapid development of milk banks, primarily for premature and low birth weight infants and for infants whose biological mothers cannot breastfeed them because they are absent or impaired in some way.

The first milk bank was started in Vienna in 1909 (Moro 2018). As PATH explains:

A human milk bank (HMB) is a service established to recruit breast milk donors, collect donated milk, and then process, screen, store, and distribute the milk to meet infants' specific needs for optimal health. The mission of an HMB is to promote and support breastfeeding by providing safe, high-quality donor milk to fill a gap for those who need mother’s milk but cannot receive it. (PATH 2019a, 13)

Some analyses address the need for regulation of human milk in all contexts including wet nursing and informal milk sales such as those arranged through the Internet (Cohen 2019). Here,

\footnotetext{
* George Kent, Deputy Editor of World Nutrition, is also its Curator of Good Questions. This is the seventh in the Good Questions series. Responses in the form of letters to the editor are welcomed.
} 
however, the focus and orientation here is on the need for regulation of activities relating to human milk banking.

This essay addresses the need for well-designed legal frameworks for regulating and supporting human milk banking (Green 2018). It draws on PATH's resource material on Strengthening Human Milk Banking, (Path 2019a; 2019b) and also the work of the Human Milk Banking Association of North America (HMBANA). The regional European Milk Bank Association (EMBA) and milk banking associations in single countries such as Italy (AIBLUD 2019; Arslanoglu 2010), Brazil (Janaina 2017), and the United Kingdom (UKAMB 2019) also provide useful reports on milk banking in their areas. Most documents focus on how milk banks operate. In contrast, this essay is about how governments and other agencies can design and implement a legal environment that supports milk banks in achieving their goals and ensuring that the public's interests are served. The regulation of milk banking should be embedded within a broader policy designed to ensure that every infant is fed in the best way possible.

Alarms are sometimes raised about human milk banks that operate in ways that appear to be exploitative, unsanitary, or provide milk to people who use it for questionable purposes. This essay reviews a variety of concerns Taken together, they indicate a clear need for regulation of milk banking, just as regulations have been developed to control the distribution of other products of human bodies (Swanson 2014).

Regulations can be used not only to limit undesired practices but also to facilitate good practices. The task is not only to limit harms, but also to increase benefits to all people and agencies that might be affected, and also to the environment, present and future. Regulating means not only setting standards for how milk banks or other agencies should operate, but also altering the structure of incentives they face by deterring bad behavior and encouraging good behavior.

Some of the major issues that should be considered in the regulation of human milk banks are discussed briefly below, in the sequence listed here. These titles of numbered sections of this paper can be understood as tentative titles for the main sections of the law that could be developed.
1. Legal Context
2. Global Guidance
3. Milk Bank Structure
4. Regulatory Systems
5. Screening Providers
6. Compensating Providers
7. Compensating Milk Banks
8. Processing
9. Screening Users
10. Commodification

These sections are followed by a brief concluding section on how the drafting of regulations for milk banks might be carried forward. 
Some opinions are offered here, but the responsibility for preparing well-designed national legislation rests with national legislatures. The primary intended audience for this discussion is national level legislators. Subnational and global agencies, both governmental and nongovernmental, should facilitate their efforts in preparing good national legislation on milk banking.

\section{Legal context}

National law on milk banking should begin with a section that explains how it is related to current relevant law at every level, global, national, and subnational. It is important to conform with existing law relating to food generally (Bone and France 2003; Urazbaeva et al. 2019; van der Meulen 2011), and also for human milk and for comparable products. In some cases, there might be a need to call for amendments to existing law to accommodate the requirements of high-quality milk banking.

Particular attention should be given to how human milk is characterized in the law. It might be described as a food, a medical product of human origin, a nutrition therapy or medical/functional food and therefore treated in accordance with the law applicable to that category, or it could be the basis for establishing a new category (PATH 2019a, 56-57).

Global agencies interested in helping national legislators draft new law on milk banking could provide systematic information on existing law in a form that is readily shared. It could adapt the format used in the U.S. Department of Agriculture's list of breastfeeding laws in U.S. states (USDA 2019. The summary of New York's law on the rights of breastfeeding mothers could be used as a model for the presentation of all laws relating to the feeding of infants and young children, with a subsection devoted to milk banking (FindLaw 20219).

\section{Global guidance}

The International Code of Marketing of Breast-milk Substitutes adopted in 1981 and the subsequent related resolutions are intended to limit the marketing of infant formula (UNICEF 2019; WHO 1981; WHO UNICEF and IBFAN 2018). With suitable adaptations, some of its principles might be applicable to the marketing of human milk as well. Future updates of the Code should address issues that arise in relation to the marketing of human milk or products made with it. Banked human milk is not a breastmilk substitute of the sort envisioned in the Code, but there is a risk that it might be sold and used in ways that raise issues of the sort addressed by the Code. As PATH emphasizes, banked human milk should be treated as a means for promoting direct breastfeeding, not as an easy alternative to it.

In 2008 the World Health Assembly, the executive body of the World Health Organization, adopted resolution WHA61.20, which included one paragraph on banked milk. It called on WHO member states. 
(4) to investigate, as a risk-reduction strategy, the possible use and, in accordance with national regulations, the safe use of donor milk through human milk banks for vulnerable infants, in particular premature, low-birth-weight and immunocompromised infants, and to promote appropriate hygienic measures for storage, conservation, and use of human milk. (WHA 2008)

The World Health Organization has recommendations for using banked milk for low-birthweight infants (WHO 2019), but not for other uses. The Food and Drug Administration in the United states has little to say about the issues (FDA 2019a).

The Codex Alimentarius Commission (Codex 2019) and the Food and Agriculture Organization of the United Nations (FAO 2019) offer many recommendations relating to food, but nothing specifically about the regulation of human milk banking.

The Food Chemicals Codex system for assessing the quality of food ingredients has not given attention to human milk (FCC 2019). The FCC is closely linked to U.S. Pharmacopeia, which is based in the United States, but its stated mission is "To improve global health through public standards and related programs that help ensure the quality, safety, and benefit of medicines and foods (USP 2019).” The global bodies may not have dealt with human milk little of it was sold and it was not traded internationally in any significant volume. However, the potential is therewhether or not we like the idea (Ramsey 2015; Smith, Julie 2017). How would current global guidance on food issues apply to human milk, and how might that guidance need to be modified?

The ICCBBA is a non-governmental organization that helps develop standards relating to terminology and labeling of health-related products. A global standard for the labeling of banked milk has been proposed, along with broad standards on milk banking (ICCBA 2018; 2019). It would be useful to press that work further in the context of developing the regulatory framework for milk banking.

\section{Milk bank structure}

National law relating to milk banks could require all banks to be organized to meet a single set of standards. Various types of organizational structures for milk banks might be considered, ranging from small volunteer operations with minimum technology to large-scale high-technology operations. Alternative organizational models could be based on the alternatives forms already described in national law. Some might be described as non-profits or charities or social benefit businesses. In the United States, perhaps milk banks could be structured as Benefit Corporations (Benefit Corporation 2019). Some milk banks might be operated by government agencies. Some might function as units physically and legally embedded within hospitals.

The focus here is on milk banking, but that does not mean such banks should function in isolation. As PATH emphasizes, milk banking should be integrated with existing maternal and infant health care systems and programs such as the Baby Friendly Hospital Initiative. Milk banks could be set up as units within community centers that provide several types of support for high-quality feeding of infants and young children, 


\section{Regullatory systems}

The simplest system for regulating milk banks is regulation directly by national governments. There are many other options. For example, milk banks could operate as part of the government, or they could function as nongovernmental organizations. They could be run independently of one another, operating as businesses or charities or some other types of agencies formally recognized in national law.

There can be several layers of government, each with distinct roles in regulation, as is common in large countries. The central government could simply ignore milk banking, or it could decisively take charge. Subnational levels of government could be assigned a role or simply take a role. In the U.S., for example, the federal government has not asserted authority over milk banks. Milk banks are regulated under state law in several states in the U.S., including California, Maryland, New York, and Texas (Ramsay 2015).

One method of regulation is through licensing or accreditation, with the milk banks held accountable through reporting and monitoring mechanisms. This can be done by government agencies, but in some cases nongovernmental professional associations could do that. Nongovernmental organizations could have milk banks as members and set standards for their certification. There is a growing trend toward this sort of regulation through private law, always embedded within the context of public (governmental) law. HMBANA provides a good illustration of the functioning of private law, accrediting milk banks in the U.S. and Canada based on a set of widely accepted guidelines.

In some countries, private law, enforced by nongovernmental agencies, plays a large role in relation to food. As a result, "based on private law, an entire legal infrastructure for the food sector emerges, in parallel to, and sometimes complementing, the public law regulatory infrastructure (van der Meulen 2011, 21). The way in which the two can work together is illustrated by state laws in the United States that say milk banks must comply with standards set by HMBANA. Formally, HMBANA standards in themselves do not have the status of conventional law. However, they gain a comparable status when they are invoked in the law. Thus, those guidelines are a form of private law.

At the national level, the Food and Drug Administration in the United States has an Accredited Third-Party Certification Program (FDA 2019b). Under some conditions the FDA can require certification of imported products.

Whether public, private, or mixed, the law for regulating milk banks should define what they are, and say what actions are allowed, required, or prohibited in authorized milk banks. There should be clear standards and effective means for monitoring and ensuring that those standards are met. 


\section{Screening providers}

Guidelines for milk banks speak about how women who offer their milk should be screened. There is a great deal of variation in screening procedures from country to country and sometimes from one milk bank to another within countries. Some variations may be warranted because of variations in local circumstances. For example, where certain diseases are rare or the need for milk is urgent, the screening procedures might be less stringent.

One major concern is that some women who are paid for their milk might for that reason deprive their own infants of it. Several measures could be taken to limit this risk:

- Issue clear instructions to providers regarding the breastfeeding of their own infants.

- Monitor the health of their infants through visits, by obtaining reports from their health care providers, or through direct examination by pediatric health care workers.

- Ensure that the price offered for human milk is not so high as to create a strong economic incentive for women to sell their own milk and instead use breastmilk substitutes to feed their own infants.

It would be useful to review all procedures for selecting milk providers to determine which of them might be established as widely agreed best practices. Then, based on that consensus, discussions could open on which of those guidelines should be established as requirements in the law.

\section{Compensating provider's}

HMBANA's mission statement says it "advances the field of nonprofit milk banking . . ..” What exactly do they mean by "nonprofit”? The same sentence says they work with "donor milk". In this context, "donor" is commonly interpreted as meaning the milk banks do not pay women for the milk they provide. Also, "nonprofit" is commonly interpreted as meaning the women are not paid for the milk they provide. EMBA also describe milk banks as collecting donor milk, "provided freely to a human milk bank."

This terminology needs to be discussed. In U.S. law, a nonprofit corporation is one in which stockholders do not earn a profit. It does not mean that people who provide goods or services cannot be paid.

I prefer the term “milk provider” rather than “milk donor” because I don't think the possibility of compensation for women who provide their milk should be excluded without full consideration. I and others have advocated a large increase in milk bank operations worldwide (Kent 2017; Schiller 2016). I think this cannot be accomplished without offering compensation to the women who provide their milk, and I find the arguments against doing that to be unconvincing. 


\section{Compensating milk banks}

Just as there are questions about appropriate types and levels of compensation from human milk banks to the women who provide their milk, there are comparable questions about who should pay what to obtain milk from the banks. In some cases, the costs might be covered by the family of the child who gets the milk. In other cases, there might be no charge at all, with the bank's operational costs absorbed by government or some other agency.

Health insurance programs have begun to cover the costs of banked milk under specific conditions. Many states in the United States now provide banked milk through the Medicaid program (Berry 2017; Campbell 2016).

In early 2019 a program was launched to cover the costs of banked donor milk for families in the U.S. armed forces (Office of the Assistant Secretary of Defense: Health Affairs 2019). They require a doctor's prescription. The costs would be covered only for milk from banks certified by HMBANA. The program does not offer coverage for banked milk obtained outside the U.S. and Canada, despite the fact that many members of the U.S. armed forces are stationed outside those countries.

\section{Processing}

There is a need to refine growing body of published guidance on human milk processing. For example, there is a need to make clear distinctions between the roles of refrigeration and pasteurization. There is some support for milk analyzers like that offered by Miris in Sweden (Medgadget 2019; Miris 2019), but others view them as expensive and unnecessary. It would be helpful if the means of processing human milk in milk banks was discussed more widely, to identify best practices and also to identify the types of processing that should be required by law.

Processing reduces the quality of the milk (Neu 2019). Regardless of the processing method, it should be recognized that feeding with human milk is not as good for infants' health as direct breastfeeding by their biological mothers. (Kakulas and Lee 2019; Meier, Patel, and EsquerraZwiers 2017). Human milk does have the potential for saving many infants' lives, but it is not correct to suggest that feeding with banked milk would be as good as optimal breastfeeding by the mother (Maweu 2019).

The PATH documents provide "standards of practice” for handling collection, pasteurization, storage, transportation and other steps to ensure that the milk is maintained at the highest possible quality. Safety is a key concern (Hartmann 2017). PATH recommends a Hazard Analysis and Critical Control Points (HAACP) process to ensure safety. HMBANA offers comparable recommendations (HMBANA 2019b). Details are available in HMBANA's document on best practices for handling human milk, available for sale at its website (HMBANA 2019c). 
Standards of practice are presented as recommendations, not laws. In a well-developed legal system, violations of the law have consequences. For example, persistent violators might have their license to operate withdrawn. Nongovernmental bodies such as HMBANA can deny membership to milk banks that appear to violate their standards, but they do not have the power to enforce any laws unless that power is delegated to them by the government.

Any law that is adopted should be clear about the arrangements for its implementation. It should include information on how violations of the law are to be detected and addressed. Some of the research tools developed by PATH and HMBANA might be adapted in the design of monitoring arrangements by government agencies.

\section{Screening users}

Who should be allowed to obtain milk from milk banks, for what purposes and under what conditions?

The highest priority is providing human milk for critically ill infants, meaning those whose lives are at risk. Most are premature and low-birth-weight infants of the sort likely to be cared for in hospital neonatal intensive care units (NICUs) where they are available. In these cases, the availability could be controlled by requiring prescriptions from doctors or through the use of other procedures used to manage the distribution of medications. Health insurance programs and their policies could have a large impact in determining what is available, for whom, and for what purposes.

If the milk supply is large enough, vulnerable infants and young children could be served as well. For example, banked milk could be provided to infants who ae not ill but cannot or are not breastfed directly by their own biological mothers. It might be beneficial to make human milk available to all infants and young children who would otherwise be fed with infant formula (Kent 2017).

Banked human milk can be used for purposes beyond meeting the basic nutritional needs of young children. For example, if milk banks were well prepared for it, banked milk could be used in emergency situations to help first responders or shelter managers support infants who have been suddenly separated from their mothers (Kent 2018). Under those conditions, the general rules for screening users could be suspended.

Before rejecting unusual users of human milk, considerations should be given to the potentials of cross-subsidization:

To illustrate, large milk banks could sell their pasteurized and bottled human milk at different prices to different categories of customers. Earnings from providing human milk for infants outside hospitals could be used to subsidize supplies for those in hospitals. Instead of simply rejecting, say, adult body builders and ice cream makers, the bank could charge them high prices. Cross-subsidies between different categories of customers could be set up, with less needy users charged 
higher prices so that more needy users could be charged lower prices. This pricing strategy was applied in early milk selling practices in the United States where, "The hope was to have enough families paying well over 17 cents an ounce to subsidize those families that paid nothing (Swanson 2014)”. (Kent 2017

One might have doubts when a breastmilk ice cream maker casually promises, "Profits are to be donated to a breastfeeding charity (El Brogy 2915)," but perhaps there are conditions under which some human milk could be sold at high prices as a means for subsidizing a supply to people with low incomes. Perhaps ethicists could be called on to help negotiate the arrangement.

Some thought should be given to the fact that human milk that doesn't meet the quality standards for use by fragile NICU infants might be safe and effective for others who are stronger. Rather than discard that milk, it could be redirected to other less vulnerable users.

\section{Commodification}

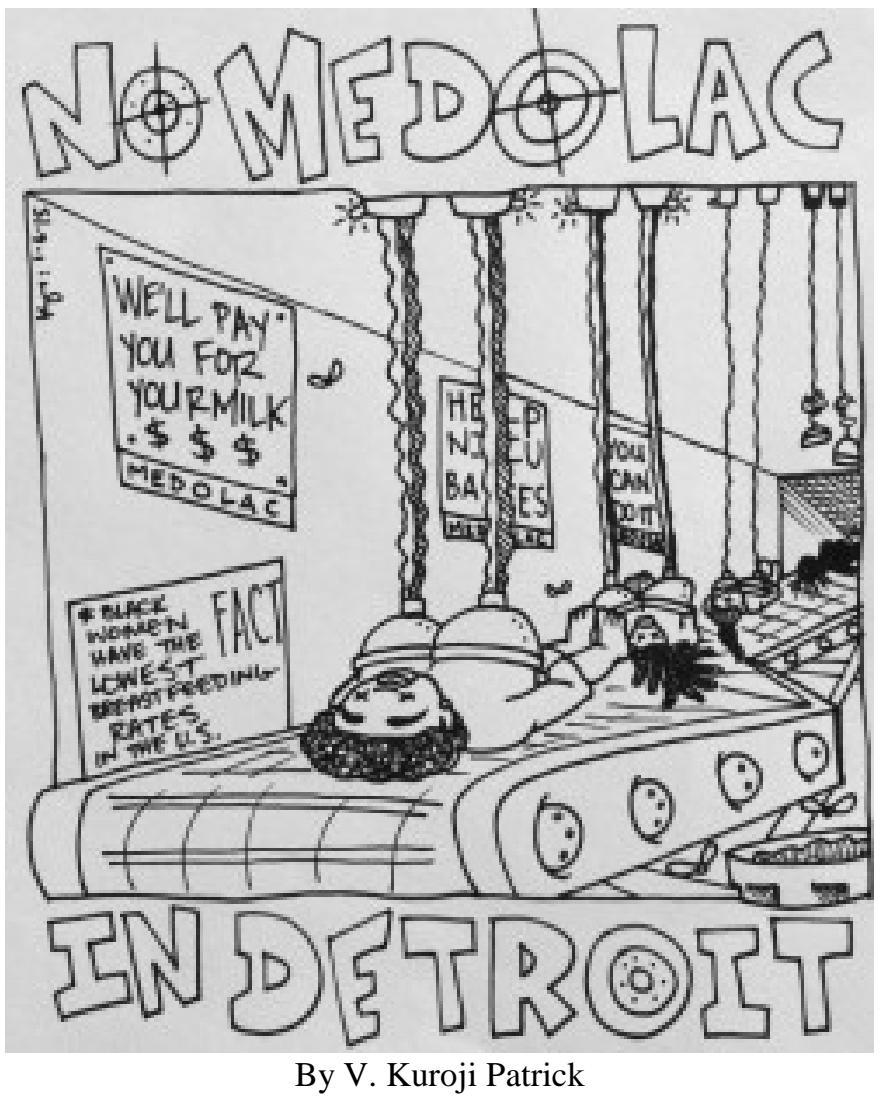

The biggest issue in screening potential users of human milk is commodification (van Esterik 2019). The term is used here to refer to the possibility that, in the absence of effective regulations to limit it, human milk and products made with it will be sold on the open market in ways that are harmful. 
The commodification process could begin at the deposit side of milk banks, with women offering their milk to whichever nearby bank offers the best price. Or where women have little power, their positions could be much grimmer, as portrayed above (Allers 2015).

This is not so far-fetched if we compare this with the familiar images of people working in stupefying factory assembly lines or cows being milked by machines in another sort of assembly line.

If there were no legal obstacles, food manufacturers could set up milk bank operations of their own to obtain human milk to include in their processed products (Allers 2014, 2015; Monteiro and Cannon 2019; Prolacta 2019a, 2019b), perhaps to be coupled to unverified claims about the health benefits it provides. If commodification is wholly unconstrained, the question of who is allowed to obtain milk from the banks could be determined by nothing more than who is willing to pay the most for it, violating the fundamental mission of milk banking to place highest priority on serving those with the greatest needs.

Where women need to go to work and are anxious about their ability to pump (Yamada, Rasmussen, and Felice 2019) and uneasy about feeding their infants with formula, they might be keen to buy human milk for their infants at the nearest milk bank or supermarket that offers it.

Many women are employed in settings in which breastfeeding is difficult or impossible. There is a long history of blocking women from breastfeeding while working in plantations and factories. There is often a racist edge to it (Collins 1803, 164-170). Some policymakers might have favored the development of infant formula in modern times in order to make a large pool of low-cost labor available.

There are many ways in which human milk can be used and misused. Human milk has been used as an ingredient for ice cream and other foods for adults (El Brogy 2019). Body builders like human milk. (Richardson 2019). Some people think athletes could improve their performance by drinking it, and others think it can cure cancer and other diseases (Samata 2017). As with many other types of food supplements, wishfulness often overrides science

Human milk can be used as an ingredient for processed products used for medical purposes, such as fortifiers for breastmilk. These can be expensive specialty products made from human milk, not to be confused with plain human milk. Many concerns have been raised about such products, such as their questionable medical value and the potentially exploitative conditions under which they are produced and sold (Allers 2014; 2015; McDonough 2015).

Human milk and products made with it could be marketed the way infant formula is now marketed, occupying prominent positions on store shelves, in various forms in the baby food section and maybe also in the cosmetics section, the food supplements section, and the dessert section. (Gretler 2019; Livemonitor 2016). Over time, an increasing share of the available human milk could go to less urgent non-medical uses. Some could be distributed as a marketed commodity, available in supermarkets and drug stores, or through online marketing. In the past there have been spotty short-lived efforts to sell human milk in open markets, but there is likely to be great pressure from commercial interests to increase this practice. With selling of liquid 
infant formula from vending machines already underway (Koe 2019), it is not difficult to imagine comparable marketing of human milk.

There were efforts to powder human milk long before modern infant formula was developed. As early as 1925, the Journal of the American Medical Association editorialized about the prospects for dried human milk. The efforts seemed entirely feasible, but JAMA judged that the efforts "cannot be said to have reached a dividend paying basis, unless one is content to count as such dividend the lifesaving quality this commodity is known to possess when given to certain sick or premature infants ..." We can only speculate about how the history of infant feeding might have been different if the value of those lives had been factored into the calculations. (Kent 2017; also see JAMA 1925; Smith, Lawrence 1924)

The market potential would become much larger if and when powdered human milk became available at a large scale, allowing the production of relatively low-cost shelf-stable products, conceivably to be produced and marketed in ways already well established for infant formula based on powdered cow's milk. Products destined for supermarkets are foreshadowed in the advertising for a shelf-stable product made from banked milk intended for use in NICUs, called HDM Boost ${ }^{\mathrm{TM}}$ (PR Newswire2019).

If nothing is done to prevent it, human milk could be treated simply as another commodity, to be sold to the highest bidder, perhaps at prices determined by greedy businesses of the sort we have seen in the food and pharmaceutical industries.

Many observers would agree that this sort of commercialization must be controlled. However, Dr. Davendra Agrawal, a leader in milk banking in India, looks at the issue in a different way:

"Perhaps it won't be possible in my lifetime," says the 70-year old, "but I want human milk powder to be available in grocery stores.

"I want it to reach that stage in India. It's so economical. When animal milk powder is available why not human milk powder?" (Patel 2014)

There are many different perspectives on milk banking that need to be reconciled.

Apart from the marketing within countries, there is potential for international trade in human milk, either in whole form, powdered form, or bottled form made from human milk powder. These prospects raise many questions. Regulators need to find ways to assess the benefits and harms and find ways to deal with them before it is too late.

One of the concerns raised in relation to international trade in human milk is that it could be highly exploitative, especially when it comes from poor countries to be sold in rich countries (Blindel 2017; Kent 2017; Smith, Julie 2017). Of course, the same question arises within countries, where the marketed product is likely to be produced by lower-income people to be used by higher-income people. 
The immediate impulse might be to reject such arrangements, but whether marketed domestically or internationally, most food products follow that pattern: the poor feed the rich (Kent 1982; 2002). Trade can be highly exploitative, but it does not have to be (Fassier 2019). One approach might be to set prices in a way that allows exports of human milk from poor to rich countries subsidize the supply of human milk for infants in those poor countries.

Some of the potential uses of human milk might be appealing, some not. The law should consider the options and say when and how various uses are to be allowed or disallowed, and under what conditions. As pointed out earlier, before rejecting unusual uses for human milk, the potentials for cross-subsidization should at least be considered.

Even if there is little hope for large-scale changes in the surrounding social and economic system, it might be possible to rearrange things in small ways at the local level. To illustrate, one way to limit the risks of exploitation might be to establish milk banks that are owned and operated by women, perhaps as cooperatives (Kent 2017). Conceivably, well-designed regulations could encourage that sort of thing while also establishing safeguards against abuse.

Some observers feel that that milk banking should be commerce free, but that could mean foregoing substantial potential benefits (Perrin et al. 2018). There are reasons for concern about commodification and profit-making (Pollack 2015), but well-regulated commerce is possible, based on distinguishing between profiting, which is acceptable, and profiteering, which is excessive. Where to the draw the line is a matter for discussion, but sometimes it is obvious.

\section{Suggestions}

Best practices and other forms of guidance can allow for considerable latitude in interpretation. While guidelines may cover a broad range of issues, regulations should cover a narrower range of issues, focusing on those for which the stakes are particularly high.

This essay highlights issues relating to the banking of human milk and advocates the development of regulations to address them. The work can begin with a review of the various milk banking guidelines already in place throughout the world. With suitable adaptations, some of them could be elevated to the status of global guidelines and national laws.

Major global governmental and nongovernmental agencies should take the lead in facilitating the long-term discussion that needs to be conducted. In the age of the Internet, that discussion could be very open, and websites could be established for sharing relevant information.

The scope of the challenge may seem overwhelming. Perhaps the key is to work incrementally, starting with the most urgent issues, in a structured framework that facilitates steady improvement in the regulation of human milk banking. With good regulation, the system could flourish in ways that provide important benefits, especially to infants and young children, with little risk of harm. 


\section{References}

AIBLUD. 2019. Associazone Italiana Banche del Latte Umano Donato (Italian Association of Human Milk Banks). Website. https://www.aiblud.com/

Allers, Kimberly Seals. 2014. "Inviting African-American Mothers to Sell Their Breast Milk, and Profiting." New York Times. December 3. http://parenting.blogs.nytimes.com/2014/12/03/inviting-african-american-mothers-tosell-their-breast-milk-and-profiting/? r=1

---. 2015. “NOMEDOLAC.” Mocha Manual: Motherhood in Color. January 13. http://mochamanual.com/2015/01/13/dear-elena-medo-you-cant-claim-to-support-blackbreastfeeding-and-attack-black-breastfeeding-advocates-now-detroit-moms-havespoken/nomedolac/

Arslanoglu, Sertac, et al. 2010. "Guidelines for the Establishment and Operation of Donor Human Milk Banks.” Journal of Maternal-Fetal and Neonatal Medicine. September. 23(S2): 1-20. https://www.tandfonline.com/doi/abs/10.3109/14767058.2010.512414?journalCode=ijmf $\underline{20}$

Benefit Corporation. Website. https://benefitcorp.net/

Berry, Anna. 2017. "Liquid Gold: 6 States Allow Medicaid Access for Breast Milk.” NPQ (Nonprofit Quarterly). April 27. https://nonprofitquarterly.org/2017/04/27/liquid-gold-6states-allow-medicaid-access-breast-milk/

Blindel, Julie. 2017. “An Example of Capitalism Literally Milking the Poor.” Truthdig. April 19. https://www.truthdig.com/articles/an-example-of-capitalism-literally-milking-the-poor/

Bone, Paula Fitzgerald, and Karen Russo France. 2003. "International Harmonization of Food and Nutrition Regulation: The Good and the Bad." Journal of Public Policy \& Marketing. April 1. 22 (1) 102-110. https://journals.sagepub.com/doi/abs/10.1509/jppm.22.1.102.17618?journalCode=ppoa

Campbell, Olivia. 2016. "When Babies Need Donated Breast Milk, Should States Pay?” Scientific American: Stat. October 4. https://www.statnews.com/2016/10/04/breast-milklaws-premature-babies/

Collins, H. 1803. Practical Rules for the Management and Medical Treatment of Negro Slaves in the Sugar Colonies. London: Vernor and Hood. https://archive.org/details/practicalrulesf00collgoog/page/n9 
Campos, Janaina. 2017. More Than 200 Human Milk Banks in Brazil and on Three Continents: Network Celebrates Growth and Success.” FIOCRUZ. http://www.fiotec.fiocruz.br/en/who-we-are

Codex. 2019. Codex Alimentarius Commission. http://www.fao.org/fao-whocodexalimentarius/en/

Cohen, Mathilde. 2019. "Should Human Milk Be Regulated.” UC Irvine Law Review. (9): 55764, https://papers.ssin.com/sol3/papers.cfm?abstract_id=3345703

El Brogy, Mars. 2015. Breast Milk Ice Cream is Back - and its Profits Will go to a Breastfeeding Charity.” Independent. April 24. https://www.independent.co.uk/life-style/food-anddrink/breast-milk-ice-cream-is-back-and-its-profits-will-go-to-a-breastfeeding-charity$\underline{10202560 . h t m l}$

EMBA. 2019. European Milk Bank Association. Website. https://europeanmilkbanking.com/

FAO. 2019. Food Regulations. Food and Agriculture Organization of the United Nations. http://www.fao.org/food/food-safety-quality/capacity-development/food-regulations/en/

FCC. 2019. Food Chemicals Codex. https://www.foodchemicalscodex.org/

FDA. 2019a. Use of Donor Milk. Washington, D.C.: U.S. Food and Drug Administration. https://www.fda.gov/scienceresearch/specialtopics/pediatrictherapeuticsresearch/ucm235 203.htm

FDA. 2019b. FSMA Final Rule on Accredited Third-Party Certification. Washington, D.C.: U.S. Food and Drug Administration. https://www.fda.gov/food/food-safety-modernization-actfsma/fsma-final-rule-accredited-third-partycertification?utm_campaign=FSMA\%3A\%20Certification\%20Body\%20LSQA\%20S.A $\underline{05062019 \& u t m \_ \text {medium }=\text { email\&utm_source=Eloqua }}$

FindLaw. 2019. New York Consolidated Laws, Public Health Law - PBH § 2505-a. Rights of breastfeeding mothers. FindLaw. https://codes.findlaw.com/ny/public-health-law/pbhsect-2505-a.html

Fassier, Joe. 2019. "Bananas are Getting Cheaper. That Low Price Comes with Hidden Costs.” The New Food Economy. May 20. https://newfoodeconomy.org/bananas-are-gettingcheaper-that-low-price-comes-with-hiddencosts/?utm_source=New+Food+Economy+Subscribers\&utm_campaign=1b1b728efdEMAIL_CAMPAIGN_2019_05_23_06_40\&utm_medium=email\&utm_term=0_75a28a 0eaf-1b1b728efd-511621101

Green, Andrew.2018. The Gap in Global Guidelines on Human Milk Banking.” Malnutrition Deeply. August 2. https://www.newsdeeply.com/malnutrition/articles/2018/08/02/thegap-in-global-guidelines-on-human-milk-banking 
Gretler, Corinne. 2019. "Nestlé Turns to Moms After 150 Years of Selling Infant Formula.” Bloomberg. https://www.bloomberg.com/news/articles/2019-03-28/nestle-turns-tomoms-after-150-years-of-selling-infant-formula

Hartmann, Ben T. 2017. "Ensuring Safety in Donor Human Milk Banking in Neonatal Intensive Care.” Clinics in Perinatology. March. 44(1): 131-149. https://www.perinatology.theclinics.com/article/S0095-5108(16)30104-X/fulltext

HMBANA. 2019a. Human Milk Banking Association of North America. Website. https://www.hmbana.org/

---. 2019b. Milk Processing and Safety. HMBANA. https://www.hmbana.org/our-work/milkprocessing-safety.html

---. 2019c. Best Practice for Expressing, Storing and Handling Human Milk in Hospitals, Homes, and Child Care Settings. $4^{\text {th }}$ Edition. Human Milk Banking Association of North America. https://www.hmbana.org/our-work/publications.html

ICCBA. 2018. ISBT 128 For Human Milk: An Introduction. $4^{\text {th }}$ Edition. https://www.iccbba.org/uploads/79/a7/79a7c2739fc7fecff6858be42db552cb/IN-031ISBT-128-For-Human-Milk-An-Introduction-v4.pdf

---. 2019. Milk Banking. ICCBA. https://www.iccbba.org/subject-area/milk-bank

JAMA. 1925. “Dried Human Milk.” JAMA (Journal of the American Medical Association) 86 (5): 352-353. http://jama.jamanetwork.com/article.aspx?articleid=239441

Kakulas (formerly Hassiotou), Foteini, and Shoo Lee. 2019. "Feeding the Preterm Infant: Fresh or Processed Breastmilk?. Splash. April. http://milkgenomics.org/article/feeding-thepreterm-infant-fresh-or-processedbreastmilk/?utm_source=Newsletter_April2019\&utm_campaign=SPLASHapril2019\&ut $\underline{\text { m_medium}=e m a i l}$

Kent, George. 1982. "Food Trade: The Poor Feed the Rich," Food and Nutrition Bulletin, 4(4): 25-33 http://www.unu.edu/Unupress/food/8F044e/8F044E05.htm

---. 2002. Food Trade and Food Rights,” UN Chronicle. XXXV (1): 27-29. http://www2.hawaii.edu/ kent/FoodTradeandFoodRights.pdf

---. 2017. “Extending the Reach of Human Milk Banking.” World Nutrition. 8(2): 232-250. https://worldnutritionjournal.org/index.php/wn/article/view/143/111

---. 2018. "Wet Nursing in Emergencies.” World Nutrition. 9(3): 314-323. https://worldnutritionjournal.org/index.php/wn/article/view/585/542 
Koe, Tingmin. 2019. “Japan’s Ezaki Glico Ramps up Solutions for Times of Emergency and Convenience.” Food Navigator-Asia. May 20. https://www.foodnavigatorasia.com/Article/2019/05/20/Vending-machine-infant-formula-Japan-s-Ezaki-Glicoramps-up-solutions-for-times-of-emergency-and-convenience

Livemonitor. 2016. "Pick N Pay to SELL fresh BREAST Milk in all Stores by 2017.” Livemonitor. November 8. http://livemonitor.co.za/fresh-breast-milk-in-stores-2017/

Maweu, Diana. 2019. “White Gold: Breast Milk Bank A Godsend to Babies.” The Star .Kenya. April 12. https://www.the-star.co.ke/opinion/columnists/2019-04-12-breast-milk-bank-agodsend-to-babies/

McDonough, Katie 2015. "The Rise of Big Breast Milk: A Boon for Healthy Babies or Exploitative of Low-Income Countries.” Salon, March 20. http://www.salon.com/2015/03/20/the_rise_of_big_breast_milk_a_boon_for_healthy_bab ies_or_exploitative_of_low_income_mothers/?source=newsletter

Medgadget. 2019. "Miris Human Milk Analyzer Cleared by FDA to Measure Nutritional Content for Donor Milk.” Medgadget. January 7. https://www.medgadget.com/2019/01/miris-human-milk-analyzer-cleared-by-fda-tomeasure-nutritional-content-for-donor-milk.html

Medical Xpress. 2015. Freeze-drying Breast Milk Retains More of its Healthy Properties. December 17. http://medicalxpress.com/news/2015-12-freeze-drying-breast-retainshealthy-properties.html

Meier, Paula, Aloka Patel, and Anita Esquerra-Zwiers. 2017. "Donor Human Milk Update: Evidence, Mechanisms, and Priorities for Research and Practice.” Journal of Pediatrics. 180: 15-21. https://www.jpeds.com/article/S0022-3476(16)30937-4/pdf

Miris. 2019. Miris Solutions. https://www.mirissolutions.com/

Monteiro, Carlos A. and Geoffrey Cannon. 2019. "The Role of the Transnational Ultra-processed Food Industry in the Pandemic of Obesity and its Associated Diseases: Problems and Solutions. World Nutrition. 10(1): 89-99. https://worldnutritionjournal.org/index.php/wn/article/view/621/54

Moro, Guido E. 2018. "History of Milk Banking: From Origin to Present.” Breastfeeding Medicine. 13 (S1) S16-S17). https://www.liebertpub.com/doi/pdfplus/10.1089/bfm.2018.29077.gem

Neu, Josef. 2019. “Mother’s Own Milk: How Does it Differ from Donor Milk for the Baby.” Breastfeeding Medicine. 14(S1). https://www.liebertpub.com/doi/pdfplus/10.1089/bfm.2019.0036 
Office of the Assistant Secretary of Defense: Health Affairs. 2019. Publications System Change Transmittal For Tricare Policy Manual (TPM), February 2008.

https://manuals.health.mil/pages/DisplayManualPdfFile/TP08/220/ChangeOnly/TP08/TP 08C-220COComposite.pdf

Patel, Atish 2014. “India’s growing breast milk banking network.” News India. July 16. http://www.bbc.com/news/world-asia-india-28106559

PATH. 2019a. Strengthening Human Milk Banking: A Resource Toolkit for Establishing and Integrating Human Milk Banks. https://www.path.org/programs/maternal-newborn-childhealth-and-nutrition/strengthening-human-milk-banking-resource-toolkit/

---. 2019b. Providing Lifesaving Breast Milk for Every Newborn. February 6. https://www.path.org/articles/providing-lifesaving-breast-milk-every-newborn/

Perrin, Maryann T. et al. 2018. “A Pilot Study on Nutrients, Antimicrobial Proteins, and Bacteria in Commerce-free Models for Exchanging Expressed Human Milk.” Maternal and Child Nutrition. 14(56):e12566. https://onlinelibrary.wiley.com/doi/epdf/10.1111/mcn.12566

Petherick, Anna. 2015. “Milk Banks Around the World.” Splash! March. http://milkgenomics.org/article/milk-banks-around-the-world/

Pollack, Andrew. 2015. "Breast Milk Becomes a Commodity, With Mothers Caught Up in Debate.” New York Times. March 20. http://www.nytimes.com/2015/03/21/business/breast-milk-productscommercialization.html? $\mathrm{r}=1$

Prolacta 2019a. Prolact+ H2MF® Human Milk Fortifier. http://www.prolacta.com/human-milkfortifier

---. 2019b. Milkbanking.net: A Prolacta Milk Banking Network. Website. http://milkbanking.net/index

Ramsey, Phoebe. 2013. “The Breast Milk Market and the Need for Clearer Rules.” O’Neill Institute for National \& Global Health Law. http://oneill.law.georgetown.edu/breastmilk-market-need-clearer-rules/

Richardson, Hayley. 2019. “NHS Warning Over 'Black-market Breast Milk': Health Bosses Hit Out at 'Utterly Horrendous' Mothers Who are selling 'Liquid Gold' to Bodybuilders for $£ 1$ an Ounce.” Daily Mail. March 11. https://www.dailymail.co.uk/femail/article6795853/Mums-selling-blackmarket-breast-milk-online-bodybuilders-calling-liquidgold.html

Samata, Cahli. 2017. “Should Adults Drink Breast Milk?” Particle. October 5. https://particle.scitech.org.au/food/should-adults-drink-breast-milk/ 
Schiller, Ben. 2016. "It's Time For A Global System Of Breast Milk Banks.” Co.Exist Daily. September 28. https://www.fastcoexist.com/3063989/its-time-for-a-global-system-ofbreast-milk-banks

Smith, Julie. 2017. "Without Better Regulation, the Global Markets for Breast Milk Will Exploit Mothers.” The Conversation. August 2. http://theconversation.com/without-betterregulation-the-global-market-for-breast-milk-will-exploit-mothers-79846

Smith, Lawrence Weld. 1924. The Experimental Feeding of Dried Breast Milk. June 17. http://www.jbc.org/content/61/3/625.full.pdf

Swanson, Kara W. 2014. Banking on the Body: The Market in Blood, Milk, and Sperm in Modern America. Cambridge, Massachusetts: Harvard University Press.

UKAMB. 2019. United Kingdom Association of Milk Banks. www.ukamb.org

UNICEF. 2019. International Code of Marketing of Breast-milk Substitutes. New York: United Nations Children's Fund. https://www.unicef.org/nutrition/index_24805.html

Urazbaeva, Altinay, Anna Sajkowska, Bart Wernaart, Nikolas Tilkin Frassens, and Rozita Spirovska Vaskoska, eds. 2019. The Functional Field of Food Law: Reconciling the Market and Human Rights. The Netherlands: Wageningen Academic Publishers.

USDA. 2019. 50 State Summary of Breastfeeding Laws. Washington D.C.: U.S. Department of Agriculture: WIC Works Resource System. https://wicworks.fns.usda.gov/resources/50state-summary-breastfeeding-laws

USP. 2019. United States Pharmacopeia. http://www.usp.org/

van der Meulen, Bernd M. J. 2011. Private Food Law: Governing Food Chains Through Contract Law, Self-regulation, Private Standards, Audits, and Certification Schemes. The Netherlands: Wageningen Academic Publishers. https://www.wageningenacademic.com/doi/pdf/10.3920/978-90-8686-730-1

Van Esterik, Penny. 2019. "Food as Cultural Core: Human Milk, Cultural Commons, and Commodification.” In Jose Luis Vivero-Pol, Tomaso Ferrando, Olivier de Schutter, and Ugo Mattei, eds. Routledge Handbook of Food as a Commons. New York: Routledge.

WHA. 2008. WHA61.20. Infant and Young Child Nutrition: Biennial Progress Report. SixtyFirst World Health Assembly. WHA61/2008/REC/1. Geneva: World Health Organization. http://apps.who.int/gb/ebwha/pdf_files/WHA61-REC1/A61_REC1-en.pdf

WHO. 1981. International Code of Marketing of Breast-milk Substitutes. Geneva: World Health Organization. http://www.who.int/nutrition/publications/code_english.Pdf 
---. 2019. Donor Human Milk for Low-birth-weight Infants. Geneva: World Health Organization. https://www.who.int/elena/titles/donormilk_infants/en/

WHO UNICEF and IBFAN. 2918. Marketing of Breast-milk Substitutes: National Implementation of the International Code: Status Report 2018. Geneva: World Health Organization.

https://www.who.int/nutrition/publications/infantfeeding/code_report2018/en/

Yamada, Rei, Kathleen M. Rasmussen, and Julia P. Felice. 2019. “What Is ‘Enough,’ and How Do I Make It?’': A Qualitative Examination of Questions Mothers Ask on Social Media About Pumping and Providing an Adequate Amount of Milk for Their Infants.” Breastfeeding Medicine. 14(1).

https://www.liebertpub.com/doi/pdfplus/10.1089/bfm.2018.0154 